\title{
Tuberculosis del Primer Trimestre de la vida
}

\author{
ABSTRACT \\ Twelve pacients admitted to the Hospital Calvo Mackenna with diagnosis Tuberculosis of the first Trimes- \\ ter of life are studied. \\ Clinical, laboratory and patological tindings are described. \\ Features used to the diagnosis of congenital Tuberculosis are analized. Based upon thuse, five sases are \\ considered as connatal Tuberculosis. \\ Tuberculosis of the first trimester of life is a patological entity that still shows diagonostic diticulties and a \\ high incidence of mortality, so it must be kept in nind every septic condition of the young infants to make an \\ accurate terapeutic attempt.
}

Conocido es el hecho de la baja sustancial y progresiva de la morbimortalidad por Tuberculosis en nuestro país., 2 Estos índices favorables son más notorios en la Tuberculosis de la infancia,

Hospital Luis Calvo Mackenna. pero persisten en el niño algunas formas de esta patología que por su gravedad mantienen indices de alta mortalidad ${ }^{3,4}$ Una de éstas es la Tuberculosis del primer trimestre de la vida.

Motivados por la importancia y escasas publicaciones actuales sobre esta forma de Tuberculo- 
sis, hicimos una revisión de los casos clínicos diagnosticados durante el primer trimestre de la vida en la Unidad de Neumotisiología del Hospital Luis Calvo Mackenna.

\section{MATERIAL Y METODO}

En nuestra revisión encontramos 12 casos desde el año 1960 hasta Marzo de 1979.

En todos ellos analizamos los siguientes datos:

Edad, Sexo, Peso al nacer, Procedencia, Antecedentes maternos, Contacto TBC, Separación de la madre, Vacuna BCG, Tiempo entre iniciación de los sintomas y diagnósticos, Síntomas y Signos, Exámenes de laboratorio, Tratamiento y estudio anatomopatológico.

\section{RESULTADOS}

De los 12 casos, 10 fueron varones y 2 mujeres; el peso al nacer sólo en 2 fue inferior a 2.500 grs. Once pacientes fallecen, el únioo sobreviviente tuvo un peso de 2.650 grs.

La procedencia correspondió en 7 casos a Santiago, 2 de origen rural y 3 de provincia.

En los antecedentes maternos destacan la existencia en 3 de ellos de Tuberculosis comprobada, una con endometritis TBC y las otras 2 con TBC, pulmonar Bacilifera diagnosticada a los 20 días y dos meses postoparto, respectivamente; en otra existía el dato de haber tenido una TBC pulmonar 2 años antes, ignorándose su estado al nomento de parto. En 3 madres se investigó TBC con resultados negativos y en el resto, vale decir $\mathbf{5}$, no se realizó investigación.

De los antecedentes de contacto intrafamiliar sólo en un caso se encontró un adulto bacilífero. En ninguno de los pacientes se tuvo conocimiento de TBC materna en el momento del parto, por lo que ninguno fue separado de la madre por esta causa; 2 de ellos fueron separados por otras razones (Ictericia, Prematurez). (Fig. 1).

Cinco pacientes fueron BCG (-), 4 BCG $(+)$ y en 3 de ellos no se consigna el dato. Seis casos llevaban más de 30 días de evolución de su enfermedad cuando ingresaron al hospital; en 5 la evolución era inferior a 15 días; en l caso se inició la sintomatología durante su hospitalización por otro motivo.

En un paciente el diagnóstico se formuló a los 15 días de haber iniciado la sintomatología, seis fueron diagnosticados después de 45 - 60 días de evolución. En 5 el diagnóstico se hizo postmorten.

Eл nueve casos los síntomas se iniciaron dentro del primer mes de vida, 4 de ellos en los primeros 15 días. (Tabla 1 ).

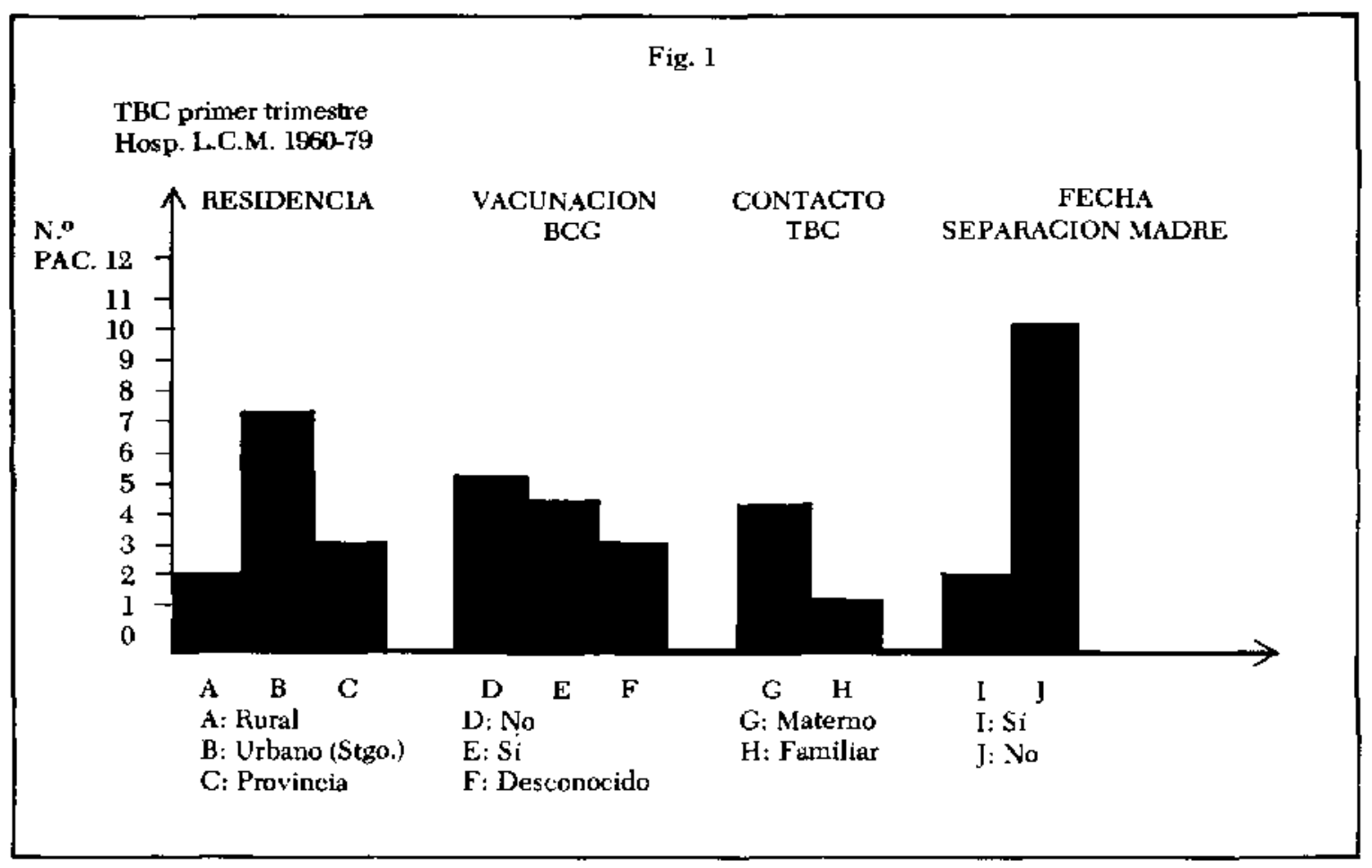


TBC primer trimestre

Hosp. L.C.M. $1960-79$

Tabla 1

\section{DISTRIBUCION POR EDAD DE APARICION DE SINTOMAS Y SIGNOS/SEXO.}

EDAD

SEXO

TOTAL

$\begin{array}{rcc} & \text { masculino } & \text { femenino } \\ 0-15 \text { días } & 3 & 1 \\ \text { 16-30 días } & 5 & 0 \\ 31-60 \text { días } & 1 & 1 \\ \text { 61-90 días } & 1 & 0 \\ & 10 & 2\end{array}$

TBC primer timestre

Hosp. L.C.M. $1960-79$
La sintomatologia fue inespecífica, destacando: Curva de peso desfavorable, Compromiso del estado general, Fiebre, Crisis de apnea y cianosis (Fig. 2).

En la signologia destacaron la hepatoesplenomegalia, luego dístensión abdominal, signos neurológicos tales como convulsiones y compromiso de conciencia. (Fig. 3). Sólo en 5 casos encontramos signología pulmonas franca con estertores finos y/o crépitos. Otros signos encontrados fueron Ictericia, Tuberculoides, Adenopatías Cervicales y/o Inguinales, Edema y Melena.

En los exámenes de laboratorio (Fig. 4) la radiografia de Tórax fue fundamental, con imáge-

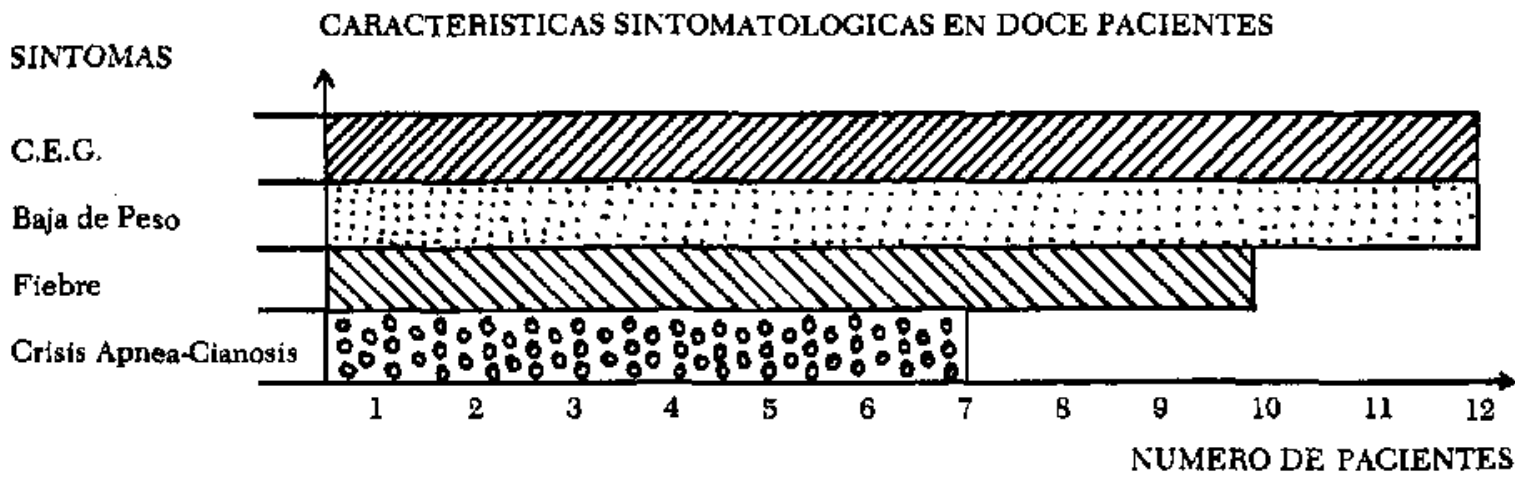

TBC primer trimestre Hosp. L.C.M. $1960-79$

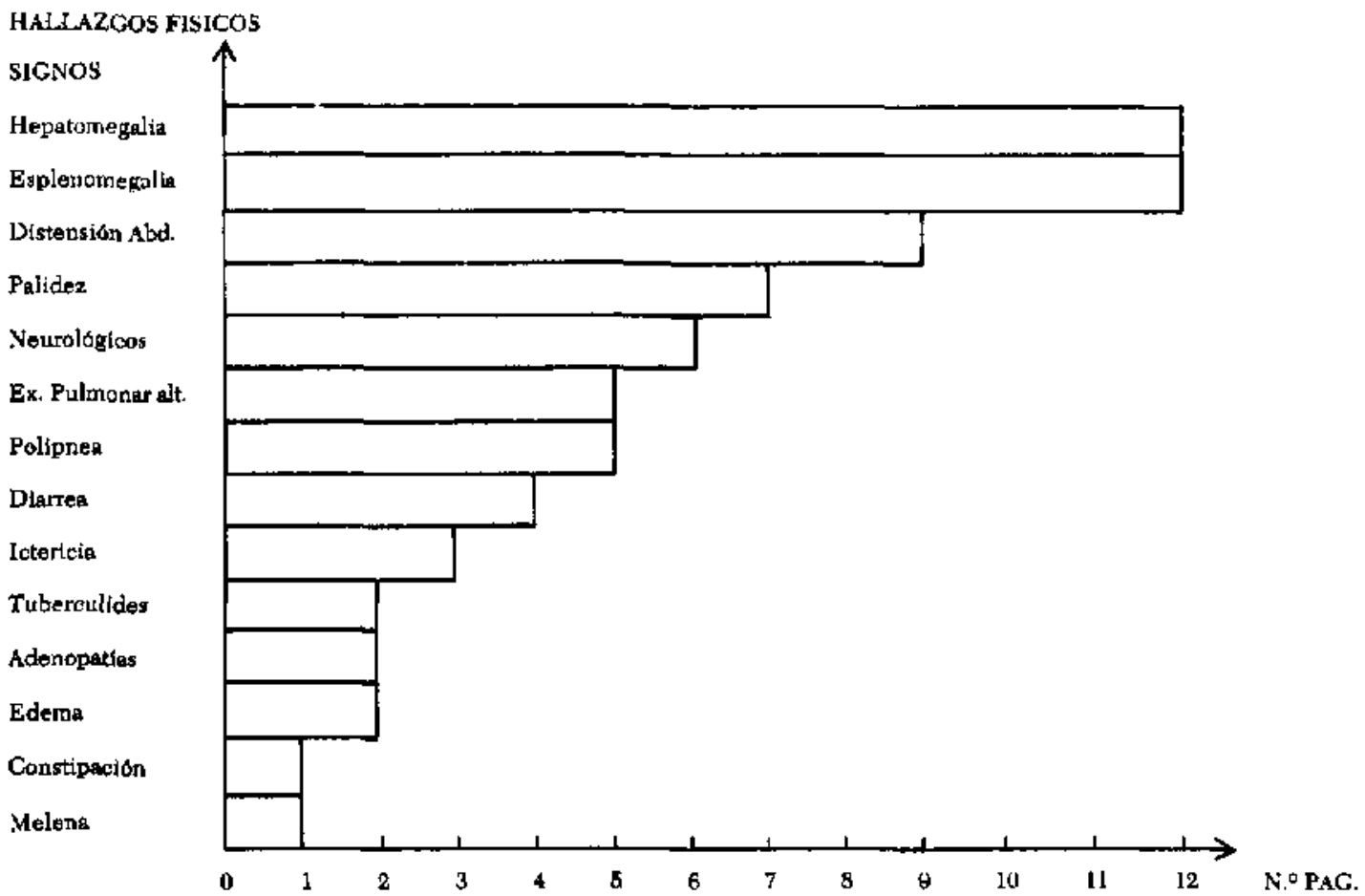




\section{CAFACTERISTICAS DE LABORATORIO}

\section{PPD}

Negativo

Positivo

No se hizo

BACILOSCOPIA

c. gástrico (+)

\section{LCR}

Citoq. normal

Citoq. alter.

Cultivo Koch (-)

Cultivo Koch (+)

HEMOGRAMA

Desv. izq.

Anemia

Hemólisis

Plaquetopenia

FONDO DE OJO

Positivo

Negativo

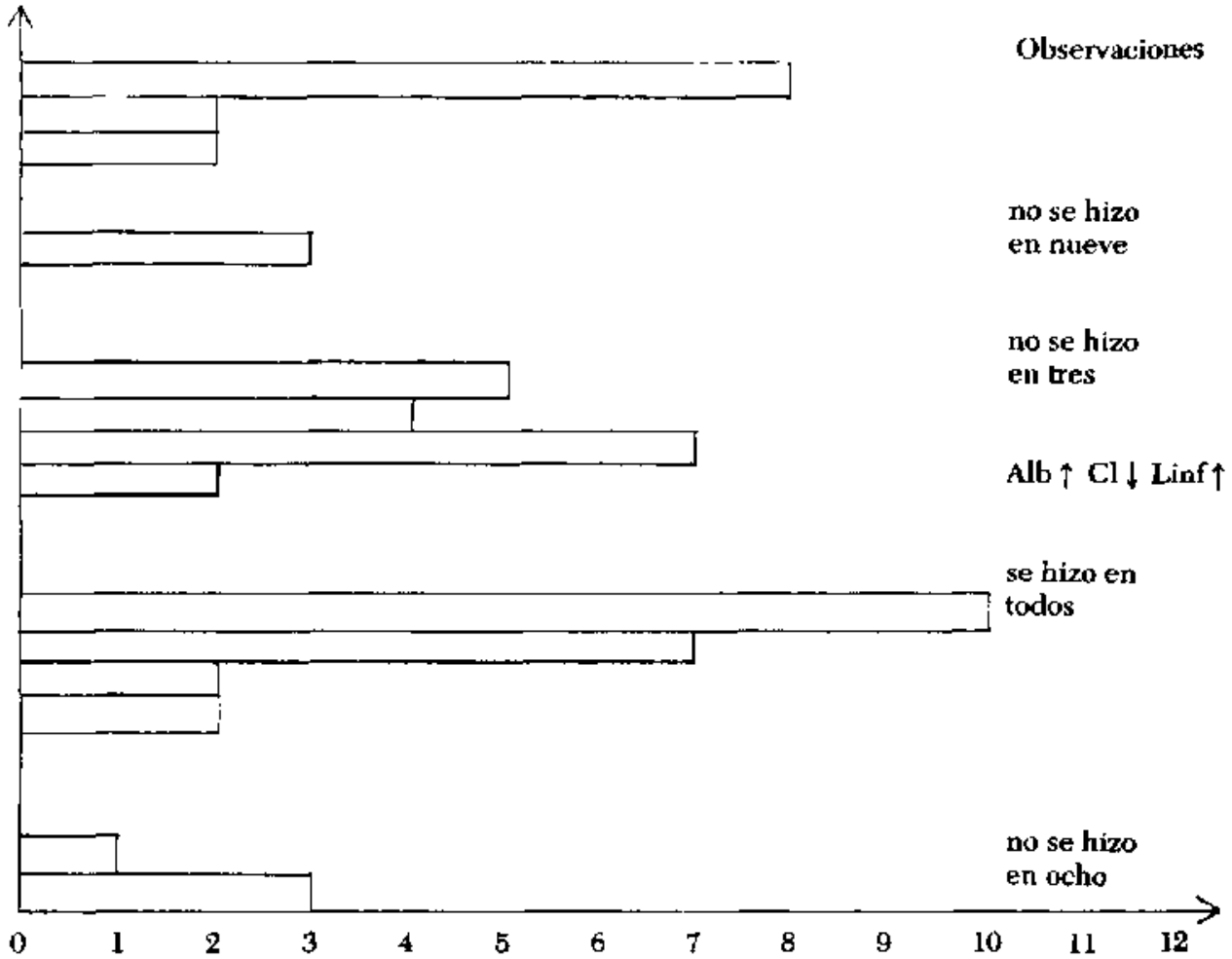

N. ${ }^{\circ}$ PAG. nes altamente sugerentes de lesión Tuberculosa, lo cual fue apoyada por las baciloscopias ya sea en contenido gástrico o en LCR.

En sólo 2 casos la Rx resultó alterada desde el ingreso, en el resto las lesiones aparecieron durante la evolución, variando el plazo entre 15 días y dos meses. En un caso persistio normal durante toda la hospitalización, correspondiendo a una forma hepatoesplénica. En 3 no se hizo por no sopecharse su diagnóstico en vida. En las lesiones encontradas destacaron imágenes miliares en 5 , condensación en 4 y adenopatías hiliares en 3 casos.

E] PPD fue negativo en todo los pacientes en que se practicó (10) virando a la positividad sólo en 2. La búsqueda del bacilo de Koch en contenido gástrico se practicó en 3 casos resultando positiva en los 3; en otros 2 el germen se encontró en el cultivo del LCR, en los demás se obtuvo en baciloscopia y/o cultivos practicados postmorten. Se hizo estudio citoquímico del LCR en 9 pacientes resultando alterado en 4 .
En un solo caso se hizo biopsia de órganos (ganglios, higado y médula) resultando positiva. En 4 casos se hizo fondo de ajo, en 1 se encontró tubérculos corórdeos.

En el hemograma se pesquisó en 10 pacientes desviación a la izquierda, en 7 anemia importante, en 2 signos francos de hemolisis y en dos plaquetopenia. Tratamiento: En 5 no se hizo por no haberse efectuado el diagnóstico en vida, los restantes recibieron variados esquemas de tratamiento, ya que nuestra casuística abarca desde el año 1960 .

Sólo en los dos últimos pacientes se usó Rifánpicina, uno de ellos sobrevive y en él se asociaron 4 drogas más corticoides.

En los enfermos que recibieron tratamiento, 5 de 7 llevaban 45-60 días de evolución y de estos 7 pacientes, 2 fallecen después de un mes de tratamiento y 5 antes de 15 días, por lo que pensamos que su fallecimiento se debe a un diagnóstico tardío en una forma grave en que no hubo tiempo suficiente para la acción terapéutica. 
En la necropsia de los 11 fallecidos, en 10 había compromiso pulmonar, en 9 diseminación a diferentes órganos destacando en todos el compromiso hepatoesplénico, ganglios mesentéricos en 6 , renal y meníngeo en 5 , intestinal en dos y en uno está descrito el compromiso de gangfios periportales. (Tabla 2).

Se comprobó postomorten el bacilo de Koch en 9 casos de muestras obtenidas de diferentes organos.

Tabla N. ${ }^{\circ} 2$

TBC primer trimestre

Hosp. L.C.M. 1960-79

HALLAZGOS ANATOMOPATOLOGICOS. (once fallecidos)

\section{ORGANOS \\ PULMONAR \\ HEPATICO}

ESPLENICO

GANGLIONAR

INTESTINAL

FENAL

MENINGEO

SUPRARRENAL

\section{COMPROMETIDOS}

enquima

periportal

mediastinico

mesentérico

cervical

\section{COMENTARIO}

Un hecho reconocido por todo los autores, es la dificultad para establecer el diagnóstico de Tuberculosis en el primer trimestre de la vida y más aún determinar su naturaleza connatal. ${ }^{3,4,5}$

Esta dificultad está dada por:

a) Desconocimiento del antecedente de Tuberculosis materna.

b) Inespecificidad de sintomas y signos de la Tuberculosis a esta edad.

c) Poca ayuda de los exánenes de Laboratorio.

En 1935 Beitzke describió el criterio que debe cumplirse para hacer el diagnóstico de Tuberculosis connatal. ${ }^{6}$

1. Debe probarse la naturaleza Tuberculosa.

2. Un complejo primario en el higado es prueba de la naturaleza connatal, ya que sólo los bacilos pueden llegar por la vía umbilical.

3. ${ }^{\circ}$ Si no hay complejo primario en el hígado la infección es connatal sólo si:

a) Existe evidencia de Tuberculosis a los pocos días de vida.

b) En los niños en que aparece en dias posteriores si la infección extrauterina puede ser

\section{NUMERO DE CASOS}

10

9

1

9

7

6

1

2

5

5

1

excluida con certeza y si el niño es separado de inmediato de la madre y llevado a un medio libre de contagio tuberculoso.

Basados en estos criterios, consideramos que 5 de nuestros 12 pacientes pueden catalogarse de Tuberculosis connatal, 4 de ellos por el comienzo precoz de los síntomas y signos (antes de los 15 días de vida) los cuales en uno se pesquisó en la madre una endometritis Tuberculosa y el $5 .^{\circ}$ por el hallazgo postmorten de complejo primario en el hígado (compromiso ganglios periportales).

La forma generalmente aceptada de transmisión de la TBC en el feto in útero es el pasaje de los bacilos desde la placenta a los vasos umbilicales y la aspiración o ingestión de liquido anniótico contaminado. Si hay aspiración la lesión primaria ocurre en el pulmón.

Si hay ingestión, el complejo primario se ubica en el tracto gastrointestinal y linfáticos mesentericos. ${ }^{7,8}$

Si la via es hematógena, el complejo primario es generalmente hepático, ya que a este órgano llega sangre más oxigenada proveniente de venas umbilicales y es sabido que el bacilo de Koch se multiplica mejor en tejidos bien oxigenados. ${ }^{5}$ (Fig. 5). 


\section{MECANISMOS TRANSMISION TBC CONNATAL}
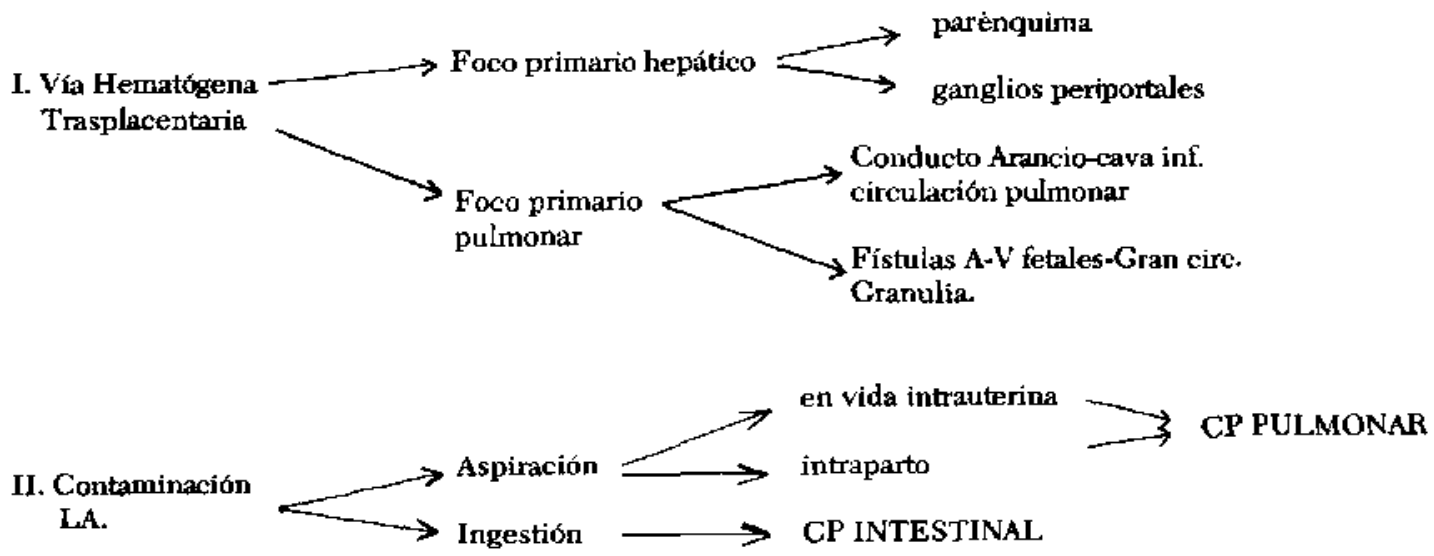

Pero no siempre el complejo primario es hepático, puede ser en otros órganos; el que se ubique en el pulmón se explica por el paso de bacilos a través del conducto de Arancio a vena cava inferior y de ahi a la circulación pulmonar, pudiendo a su vez diserninarse a travès de las comunicaciones (Foramen oval y Ductus) a la gran circulación. ${ }^{3}$

La TBC placentaria es más común que la TBC connatal, porque a menudo se produce trombosis de los vasos fetales que drenan el área de modo que la enfermedad no se transmite al feto. ${ }^{3}$

Muchas madres tuberculosas dan a luz a hijos no tuberculosos y las que lo hacen es porque se trata de una TBC avanzada, aunque a veces no se encuentra evidencia materna. ${ }^{3}$

La Tuberculosis del primer trimestre es similar a otras infecciones de esta edad, con poca tendencia a localizar procesos por los mecanismos inmunológicos deficientes, por lo tanto muchas veces los síntomas se presentan al tìnal cuando la enfermedad se disemina. ${ }^{3}$

Los sintomas y signos que se relatan en la literatura son similares a los encontrados en nuestra revisión. ${ }^{10,11,12,13}$

A continuación describiremos un caso en el que se comprobó complejo primario hepático.

C.E.I. sexo masculino, peso nacimiento 3.570 grs. asintomático hasta el sexto día en que inicia fiebre agregándose 10 días más tarde hepatoesplenomegalia que alcanza a los dos meses, 8 y 6 centímetros, respectivamente. A los 40 dias de vida: opistótono, hipertonía e hiperreflexia. Es trasladado de su hospital de origen (Chuquicamata), a nuestra Unidad a la edad de 1 mes 27 días.

Se practico radiografía de tórax que fue normal al ingreso, posteriormente reveló imágenes de condensación. Hernograma: Anemia hemolítica, Leucocitosis y Desviación izquierda. LCR: Compatible con Meningitis TBC. PPD negativo.

Al 18. dia del ingreso se plantea el diagnóstico de TBC iniciándose tratamiento a pesar del cual fallece a los 10 días de comenzado éste.

Diagnóstico Anatomopatológico.

1. Hemorragia Meníngea. 2. Encéfalo-malasia. 3. TBC Hepatoesplénica. 4. TBC pulmonar exudativa. 5 TBC ganglionar abdominal con compromiso de ganglios periportales. 6. TBC connatal trasplacentaria.

La pesquisa epidemiológica demostró madre portadora de TBC pulmonar bacilífera a los dos meses post parto.

\section{RESUMEN}

Se analizaron 12 pacientes con Tuberculosis diagnosticada durante el primer trimestre de la vida ingresados al hospital Luis Calvo Mackenna entre los años 1960 y 1979.

Se describen las características clínicas, de laboratorio y hallazgos anatomopatológicos.

Se analizan los criterios usados para catalogar 
una Tuberculosis de connatal. Basados en éstos, se consideran que 5 casos corresponden a Tuberculosis connatal.

La Tuberculosis del primer trimestre de la vida constituye una entidad que sigue siendo de dificil diagnóstico y de alta mortalidad por lo que debe tenerse presente en todo estado infeccioso no precisado del lactante menor para instaurar un tratamiento adecuado.

\section{REFERENCLAS}

1Servicio Nacional de Salud, Normas de preveacion, Tratamiento y Control de las enfermedades respiratorias de ha infancia y Tuberculosis infantil. Chile, 1974.

2Pierry. A.: Estado actual del problemn de la TBC ex Chile. Boletin chileno de Neumotisiologia, 34: 138, 1969.

3 Ariztía, A.: Sobre el problema de la Tuberculosis en el pri- mer trimestre de la vida Arebivos Argentinos de Pediatria, I: $1-43,1040$.

${ }^{4}$ Romero, M., Schilager, G; y Fanta, E.; La Tuberculosis en el primer trimestre de la vida. Pediatria, 14: 157, 1971.

${ }^{5}$ Harley, J.: Congenital TBC. Archives of disease of Child. hood, 167: 172, 1052.

${ }^{6}$ Beitzke, $H$. . Veber die ungeborene Tubereulose infection. Ergebn. d. Ges. Tuberk. Forchs, 7: 1, 1935.

TDavis, S; Finlev, S; y Kendrich, J: Congenital Tuberculosis. The joumal af Pediatries, 57: 221, 1960.

${ }^{8}$ Coshman, J: Congenital Tuberculosis. Proceedings of the Royal Socjeby of Medicine, 52: 297, 1954.

$9_{M C}$ Laren, f.: Congenital TBC, Report of a Case with unusual features. Tubercle, $41: 71,1960$.

10 Hudson, F.: Clinical features of Congenital TBC. Archives of disease in Childhood, 136: 139, 1956.

$1_{\text {Kendig, E. Jr, }}$ TBC in the very young. The Amerkans Review of TBC, 70: 161, 1954 .

12 Kerdig, E.Jr.; y Rodger, W.: Tuberculosis in the neonatal period. The American Review of Tuberculosis and pulmanary disesses, 77: 418, 1858.

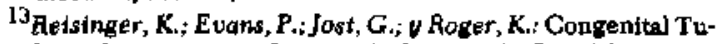
berculosis, Heport of a case. Pediatrics, 34: 74, 1974 .

\section{IgA Secretora en saliva de niños infectados por Giardia lamblia y en niños controles*}

\section{PARTE}

Dres. Isabel Noemi, ${ }^{(1)}$ Clara Retamal, ${ }^{(1)}$ Eraesto Guiraldes, ${ }^{(2)}$ Hernán Reyes, ${ }^{(1)}$ Liliana Rebol]edo, ${ }^{(2)}$ Patricia Munoz, ${ }^{(3)}$ Carmen Gutiérrez, ${ }^{(2)}$ Gabriela Mauro, ${ }^{(2)}$

\section{SUMMARY}

The levels of secretory IgA in spittle was determined by the radial immune difussion in agar in 77 children parasitied by Clardia Lambilia and in 146 bealthy children.

$U_{p}$ to 4 years old, no important difference was shown among infected children, nor in the healthy ones. From this age on infected children presented average values of secretory $\lg A$ highly superior than those of the group "control". There was a notable lack of secretory IgA in 6 infected children, all them symptomatic.

These results are commented in relation to what is alseay known according to relationships between humoral immunity response and infection by Giardis lamblia.

\section{RESUMEN}

En 77 niños parasitados por Giardia lamblia y en 146 niños controles sanos, fueron determinados los niveles de IgA secretora en saliva por el método de inmunodifusión radial en agar.

\footnotetext{
*Trabajo presentado al I Simposio Internacional de Parasitologia, Stgo. 25-29 de Octubre de 1977.

Financiudo gor el Servicio de Desarrollo Cientifico Artistico y de Cooperación Intemacional de la Universidad de Chile con e) N 123-781.

(1) Unidad de Parasitología, Depto, de Salud Pública, Facultad de Medicina, Sede Santiago Otiente. Universidad de Chile.

(2) Depto. de Pediatria. Facultad de Medicina, Sede Santiago Oriente. Universided de Chile.

(3) Unidar de Parasitologia. Depto. de Medicina y Preclínicos.

Sede Sentiago Occidente. Lniversidad de Chile.
}

Hasta los 4 años no se demostró diferencias significativas entre niños infectados y sanos. A partir de esta edad, los ninos parasitados presentaron valores promedios de IgA secretora significativamente superiores a los del grupo control. E: 6 niños parasitados, todos sintomáticos, existio una franca deficiencia de IgA secretora.

Estos resultados son comentados en relación a lo que se conoce respecto a las relaciones entre respuesta inmune humoral e infección por Giardia lamblia.

En nuestro país, la prevalencia de infección Giardia lambiia alcanza cifras que oscilan entre $10-20 \%$ en la población general $1,2,3,4$ y de un 20 a un $60 \%$ en la población infantil, ${ }^{5.6}$ siendo los ninos de corta edad los más afectadas. Sin embargo, 